\title{
Impact of Horizontal Grid Resolutions for Thunderstorms Simulation over Bangladesh Using WRF-ARW Model
}

\author{
Md. Joshem Uddin ${ }^{1 *}$, M.A. Samad ${ }^{1}$ and M.A.K. Mallik ${ }^{2}$ \\ ${ }^{I}$ Department of Applied Mathematics, University of Dhaka, Dhaka-1000, Bangladesh. \\ ${ }^{2}$ Bangladesh Meteorological Department, Agargaon, Dhaka-1207, Bangladesh.
}

(Received : 22 October 2020; Accepted : 24 February 2021)

\begin{abstract}
In this paper, an attempt has been made to study the physical and dynamical characteristics of three thunderstorms that occurred on 06 May 2017 over Mymensingh, Chuadanga, and Sylhet in Bangladesh by the WRF-ARW model of 5 and $10 \mathrm{~km}$ horizontal resolutions, and to find out the impacts of horizontal grid resolution for simulating thunderstorm events. The model was run for $48 \mathrm{~h}$ using global Final Analysis (FNL) data. Various meteorological parameters such as Mean Sea Level Pressure (MSLP), wind pattern at several pressure levels, relative humidity, and radar reflectivity along with the atmospheric instability index are analyzed and compared with the observed data of Bangladesh Meteorological Department (BMD). The model has captured the low pressure area, the conjugation of easterly and westerly wind, the presence of strong convection, high magnitude of vertical wind shear, marked dry-line, updraft, and downdraft reasonably well for the finest grid resolution. But the convective available potential energy (CAPE) value is found almost similar near the places of occurrence for both resolutions. The model performance is found precisely well for the finest than that of coarse horizontal grid resolution.
\end{abstract}

Keywords: Thunderstorms, WRF, CAPE, Grid resolutions, Dry-line, MSLP, Relative humidity

\section{Introduction}

Thunderstorm (TS) is a very common weather phenomenon in Bangladesh. From the analysis of 36 years (1980-2016) TS data provided by BMD, it is found that most of the TS occur during Pre-monsoon season. Nowadays, TS during this season become more deadly and devastating. There were 106 deaths and 72 injuries recorded per year from 2000-2009 whereas number of deaths and injuries were 260 and 211 per year respectively from $2010-2017^{1}$. Thunderstorm during pre-monsoon season is locally known as "Kalboishakhi" or "Nor-Wester" since they travel from north-west to south-east directions ${ }^{2}$. The mean thunderstorm days over Bangladesh increase significantly as the season progresses from March to May and are maximum in $\mathrm{May}^{3}$. Thunderstorm produces heavy rainfall, lightning, thunder, hail-storms, dust-storms, squalls, down-bursts and sometimes tornadoes, which critically hamper our economy.

For understanding the thermodynamic features and forecasting the TS events, studies of TS was started in the middle of the 20th century. In an earlier stage, isentropic charts were used to forecast thunderstorm events ${ }^{4}$. Reynolds et al. tried to determine the basic physical process which gives rise to thunderstorm electrification through a laboratory demonstration of this process ${ }^{5}$. From the investigation of the severe thunderstorm (super-cell storms) as related to tornadogenesis, it was concluded that there is a consistent pattern of tornadogenesis ${ }^{6}$. Lilly made an attempt to develop numerical prediction for convective storms and storm environments and describes scientific challenges along with some early progress of numerical weather prediction (NWP) ${ }^{7}$. The severe convective events over Bangladesh and the Indian region were generated by numerical weather prediction (NWP) models other than WRF with some limitations in the timing and location of the occurrence of thunderstorms ${ }^{8,9}$. Nowadays, among the various NWP model, the WRF model is widely used to study various meteorological phenomena including thunderstorms ${ }^{11,12,13}$. The characteristics of Nor'westers (severe thunderstorms) observed over northeast India and adjoining Bangladesh during the pre-monsoon season are studied based on synoptic, Radar and Tropical Rainfall Measuring Mission (TRMM) observations and simulated using the WRF model ${ }^{14}$. In all this study, the WRF model is able to capture TS events precisely well with some error in the timing and location of occurrence. To minimize this error, various authors tested the sensitivity of various physics schemes to simulate severe thunderstorms by using WRF Model ${ }^{15,16}$.

The present study comprehensively examines the impact of horizontal grid resolution for simulating thunderstorm events over Bangladesh by using the WRF-ARW model. It is believed that the present study will greatly impact the forecasting of thunderstorm events in Bangladesh.

\section{Events Description}

In this study, three thunderstorm events have been taken for the NWP study, which occurred on 06 May 2017 over Mymensingh, Chuadanga, and Sylhet at 1530 UTC, 1340 UTC, and 1610 UTC respectively. The synoptic features during the event under investigation collected from Meteorological \& Oceanographic Satellite Data Archival Centre (MOSDAC) are shown in Figure 1(b). From this image, the presence of a large convective cloud is found from southwest to northeast over Bangladesh and its adjacent area. The locations of the meteorological stations of BMD near the place of occurrence are shown with latitude and longitude in Figure 1(a). The meteorological records of the nearby station show that all thunderstorms were severe thunderstorms, with northwesterly gusty wind. The wind speed at 10 meter height was $56 \mathrm{kmh}^{-1}$, $65 \mathrm{kmh}^{-1}$ and $59 \mathrm{kmh}^{-1}$ over Chuadanga, Mymensingh and Sylhet respectively. For this thunderstorm event, 27 
$\mathrm{mm}, 13 \mathrm{~mm}$, and $28 \mathrm{~mm}$ rainfall was recorded by BMD over Mymensingh, Chuadanga, and Sylhet on that day, and the recorded mean sea level pressure was $1006 \mathrm{hPa}$ at 1500 UTC, $1006 \mathrm{hPa}$ at $1200 \mathrm{UTC}$ and $1008.3 \mathrm{hPa}$ at $1500 \mathrm{UTC}$ respectively.

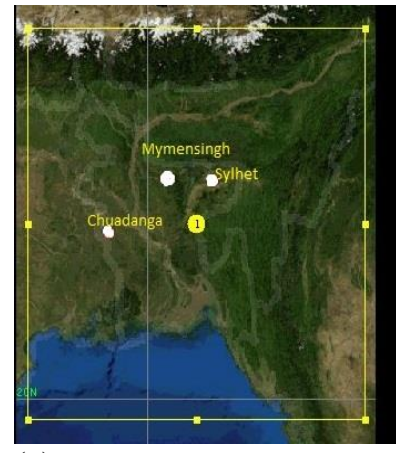

(a)

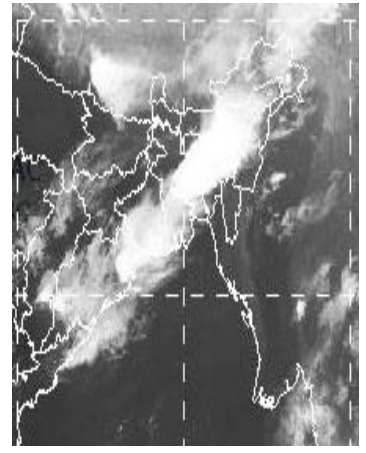

(b)
Fig. 1. (a) Location of the TS event area on the domain. (b) Satellite image over Bangladesh on 16 may 2017 at 1545 UTC collected from Meteorological and Oceanographic Satellite Data Archival Centre (MOSDAC).

\section{Data and Methods}

The NCEP FNL (Final) Operational Global Analysis data and Global Forecast System (GFS) data both can be used to run the WRF-ARW Model ${ }^{11,17}$. The NCEP FNL (Final) Operational Global Analysis data are on 1-degree by 1degree grids prepared operationally every six hours ${ }^{18}$. In the present study, the FNL Operational Global Analysis data from 05 May 20170000 UTC to 07 May 20170000 UTC produced by NCEP are used as the initial and lateral boundary conditions. Also, the observed data, recorded by the Bangladesh Meteorological Department (BMD) is used to validate the model simulated results.

For detail information about the WRF model and how to run the ARW system, ARW User's Guide has the details on its operation ${ }^{19}$. In this study Yonsei University (YSU) planetary boundary layer scheme, rapid and accurate radiative transfer model (RRTM) long wave radiation scheme, Dudhia short wave radiation scheme and Unified Noah land surface model (LSM) scheme is used following Karmakar et al. and Kessler Microphysics scheme is used following Zeyaeyan et al. for the simulation of the thunderstorms events ${ }^{11,17}$. Before this study, a comparison between Kain-Fritsch, Grell 3D and Grell-Devenyi (GD) ensemble cumulus physics scheme is made by the authors, where the GD ensemble scheme performs better than that of the other two. Hence the GD ensemble scheme is used as a cumulus physics option for this study. $5 \mathrm{~km}$ horizontal resolution is chosen following Zeyaeyan et al. Since we want to compare the accuracy of high resolution and low resolution, $10 \mathrm{~km}$ resolution is also used to run the model. An overview of the model configuration for the present study is shown in Table 1.
Table 1. Overview of WRF model configurations Dynamics and Domain

\begin{tabular}{|c|c|}
\hline WRF core & ARW \\
\hline DATA & NCEP-FNL \\
\hline Number of Domain & 1 \\
\hline Run time & $48 \mathrm{hr}$ \\
\hline Interval & $30 \mathrm{~min}$ \\
\hline $\begin{array}{l}\text { Central point of the } \\
\text { Domain }\end{array}$ & $23^{\circ} \mathrm{N}, 90^{\circ} \mathrm{E}$ \\
\hline Horizontal resolution & $5 \mathrm{~km}$ and $10 \mathrm{~km}$ \\
\hline \multirow{2}{*}{ Grid size } & $250 \times 250 \times 38$ for $10 \mathrm{~km}$ grid spacing \\
\hline & $500 \times 500 \times 38$ for $5 \mathrm{~km}$ grid spacing \\
\hline Map projection & Mercator \\
\hline Integration time step & $45 \mathrm{~s}$ \\
\hline Vertical coordinate & pressure vertical coordinate \\
\hline Time integration scheme & 3rd order Runge-Kutta \\
\hline $\begin{array}{l}\text { Spatial differencing } \\
\text { scheme }\end{array}$ & 6th order centered difference \\
\hline \multicolumn{2}{|c|}{ Physics options } \\
\hline Microphysics & Kessler scheme $^{20}$ \\
\hline PBL Parameterization & Yonsei University (YSU) scheme ${ }^{21}$ \\
\hline Surface layer physics & Revised MM5 scheme ${ }^{22}$ \\
\hline Land-surface model & Unified Noah LSM $^{23}$ \\
\hline Short wave radiation & Dudhia scheme $^{24}$ \\
\hline Long wave radiation & RRTM scheme $^{25}$ \\
\hline Cumulus parameterization & $\begin{array}{lll}\begin{array}{l}\text { Grell-Devenyi } \\
\text { scheme }^{26}\end{array} & \text { (GD) ensemble } \\
\end{array}$ \\
\hline
\end{tabular}

\section{Results and Discussions}

Various meteorological parameters associated with formation and development of thunderstorms such as mean sea level pressure, radar reflectivity, wind pattern, etc., along with the instability index CAPE during the thunderstorm events on 06 May 2017 over Chuadanga, Mymensingh, and Sylhet performed by the WRF-ARW model, is deeply analyzed in this section for $5 \mathrm{~km}$ and 10 $\mathrm{km}$ horizontal grid size and try to make a comparison between this two horizontal grid resolution. The validation of the model output is made by comparing with the observed data and tries to find out the impact of horizontal resolution on the model performance. According to the model, the thunderstorm was formed at around 1530 UTC, 1730 UTC and 1830 UTC over Chuadanga, Mymensingh, and Sylhet respectively for $5 \mathrm{~km}$ resolution.

In the case of a $10 \mathrm{~km}$ resolution, the model does not capture TS over Chuadanga properly and over Mymensingh and Sylhet around 1830 UTC and 2100 UTC respectively while in reality, it occurred at around 1340 UTC, 1530 UTC and 1610 UTC over Chuadanga, Mymensing, and Sylhet respectively. The model results show the formation at around $2 \mathrm{~h}$ later than the actual time of occurrence for $5 \mathrm{~km}$ resolution and it is around $3 \mathrm{~h}$ and $4.5 \mathrm{~h}$ later over Mymensingh and Sylhet respectively for $10 \mathrm{~km}$ resolution.

\section{Mean Sea Level Pressure (MSLP) Analysis}

Mean sea level pressure is one of the most important ingredients for the formation of a thunderstorm. A lowpressure area helps the air parcel rises and to form the 
cumulonimbus cloud which is associated with a thunderstorm. A low-pressure area of $1006 \mathrm{hPa}$ is found to the adjoining area of Chuadanga, Sylhet, and Mymensingh at 1330 UTC, 1430 UTC, and 1530 UTC respectively by WRF-ARW model for $5 \mathrm{~km}$ horizontal resolution. The MSLP to the other part of the country is comparatively high during this time. This low pressure over this area is then gradually increased with time and becomes $1011 \mathrm{hPa}$ over Chuadanga at 1600 UTC and $1012 \mathrm{hPa}$ over Mymensing and Sylhet at 1730 UTC and 1800 UTC respectively.

But in the case of $10 \mathrm{~km}$ horizontal resolution, this lowpressure area is not captured precisely well than that of 5 $\mathrm{km}$ horizontal resolution. The model simulated MSLP near Chuadanga, Mymensingh and Sylhet is $1006 \mathrm{hPa}, 1008 \mathrm{hPa}$ and $1009 \mathrm{hPa}$ at 1330 UTC, 1430 UTC and 1530 UTC respectively which is comparatively high. The model simulated MSLP of 06 May 2017 based on the initial conditions of 0000 UTC of 05 May for $5 \mathrm{~km}$ and $10 \mathrm{~km}$ horizontal resolution is shown in Figure 2.

\section{Analysis of Wind Pattern and Direction at $850 \mathrm{hPa}$ Level}

Wind speed and direction is one of the most important ingredients of thunderstorms. When a low-pressure area is created over a particular area then the wind started to blow towards this area from the surrounding region which is responsible for upward convection. During a thunderstorm, a strong wind blows over the event area and sometimes become very devastating. From the model simulated wind speed and direction for $5 \mathrm{~km}$ horizontal resolution, a conjugation of westerly and easterly wind is found over the adjoining area of Chuadanga, Mymensingh, and Sylhet at 1330 UTC. This conjugation helps to form the thunderstorms cloud. The model output also shows that a strong wind of speed more than $50 \mathrm{kmh}^{-1}$, blow over the northern part of the Chuadanga at 1530 UTC and over Mymensingh at 1730 UTC which is then gradually moved toward Sylhet and passes at 1830 UTC. So it is found that the model is capable to simulate strong wind speed but it is almost two hours later than that of the observations.

For $10 \mathrm{~km}$ horizontal resolution, a conjugation is also found just over the western part of Chuadanga at 1350 UTC. And the strong wind is found over Mymensingh at 1830 UTC which is almost 3 hours later and over Sylhet at 2100 UTC which is almost 4.5 hours later than that of the observation. So model simulation result shows that model gives the better result to simulate wind speed and direction for $5 \mathrm{~km}$ horizontal resolution. Model simulated wind speed and direction at $850 \mathrm{hPa}$ level of 06 May 2017 based on the initial conditions of 0000 UTC of 05 May for $5 \mathrm{~km}$ and 10 $\mathrm{km}$ horizontal resolution are shown in Figure 3.

\section{Wind shear Analysis between $850 \mathrm{hPa}$ Level and $200 \mathrm{hPa}$ Level}

Vertical wind shear is a critical factor for the development of severe thunderstorms. Strong vertical wind shear are favorable for formation of TS events over Bangladesh region $^{27}$. Strong vertical wind shear keeps separate the updraft and downdraft which alive the thunderstorm. From the analysis of wind shear between $850 \mathrm{hPa}$ level and 200 $\mathrm{hPa}$ level for $5 \mathrm{~km}$ horizontal resolution, a strong vertical wind shear of $36 \mathrm{kmh}^{-1}$ is found over the adjoining area of Chuadanga and Mymensingh at 1330 UTC. During this time, the wind shear to the other part of Bangladesh is $15 \mathrm{kmh}^{-1}$ or even lower as shown in Figure 4. This strong vertical wind shear is then gradually moved to the northwestern direction. Then a negative wind shear is created over the northern part of Chuadanga at 1530 UTC and over Mymensingh at 1700 UTC which gradually moves toward Sylhet and passes at 1830 UTC. This negative wind shear indicates that strong wind blows over the surface area during that time and gradually thunderstorms die out.

The model also captures the strong vertical wind shear for $10 \mathrm{~km}$ horizontal resolution but it is not good enough like 5 $\mathrm{km}$ horizontal resolution.

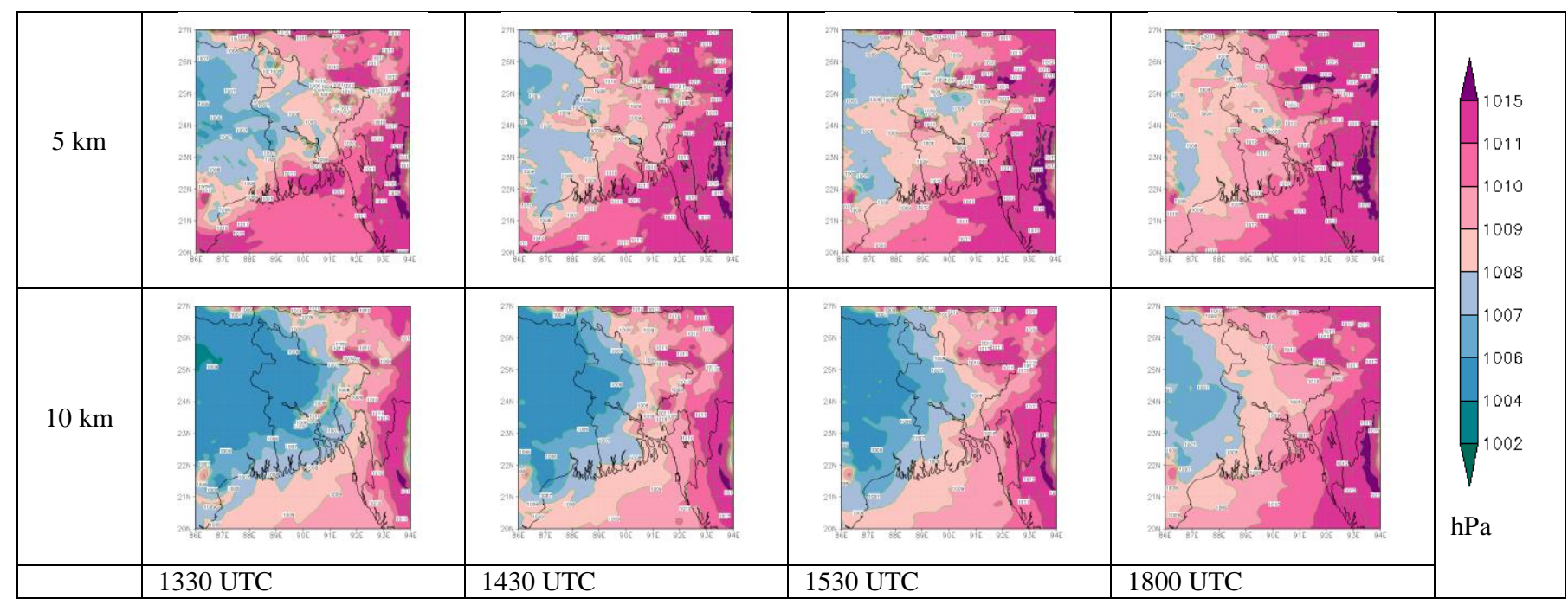

Fig. 2. Model simulated MSLP of 06 May 2017 performed by WRF-ARW model 


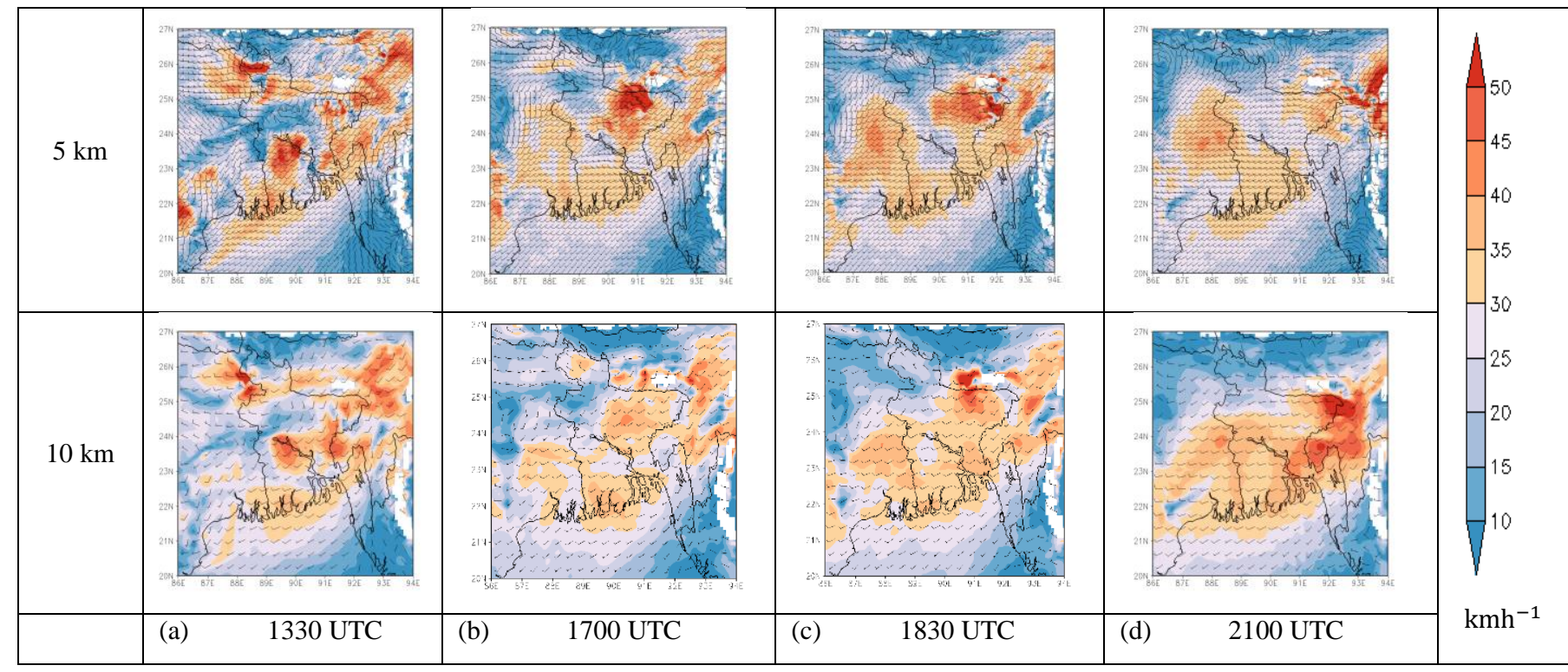

Fig. 3. Model simulated wind speed and direction at $850 \mathrm{hPa}$ level of 06 May 2017 at different time.

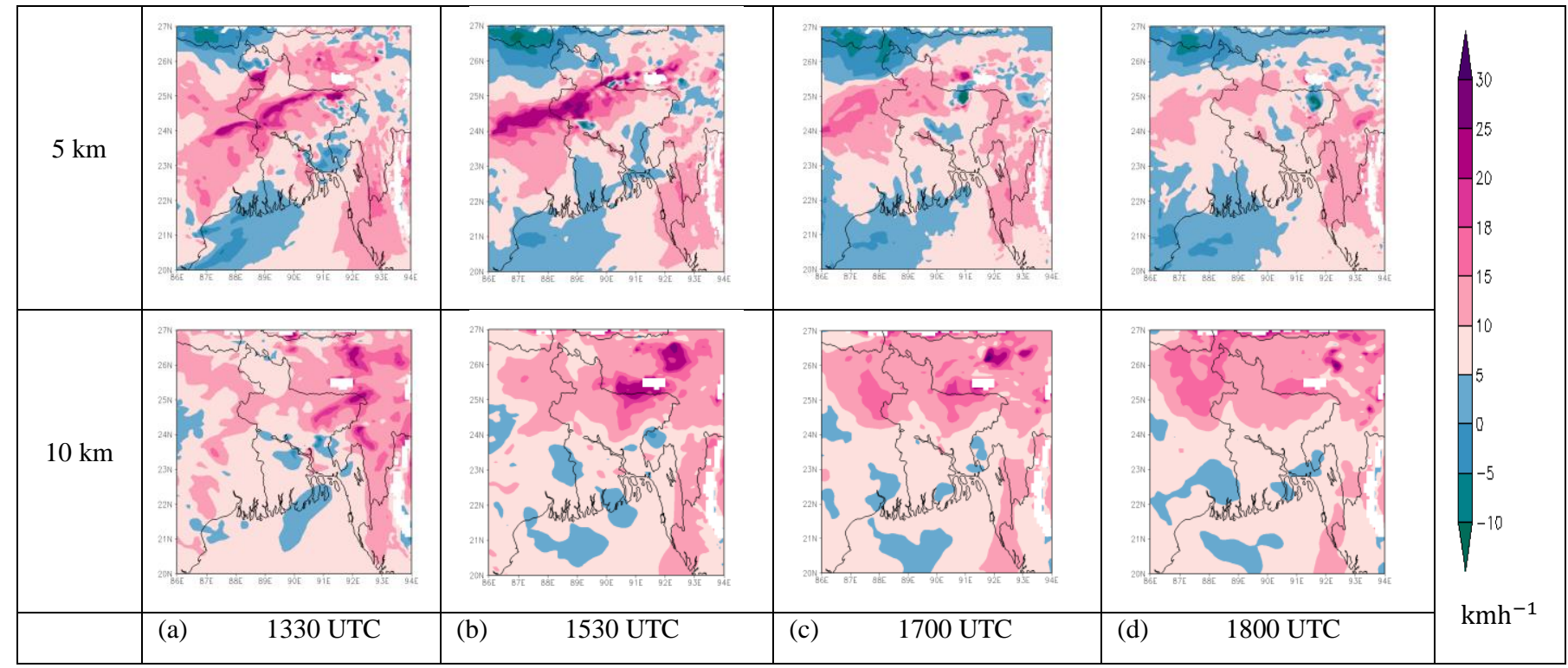

Fig. 4. Model simulated vertical wind shear between $850 \mathrm{hPa}$ and $200 \mathrm{hPa}$ level of $06 \mathrm{May} 2017$ at different time.

Analysis of Relative Humidity at $2 m$ Height and Identification of Dry Line

The surface level relative humidity is an essential factor for intense convection. Storm days require a sufficiently humid and deep layer in the lower and middle atmosphere. Dryline which is related to relative humidity is responsible for the formation of a thunderstorm. Thunderstorms mainly occurred on the right side of the dryline. From the model simulated relative humidity at $2 \mathrm{~m}$ height for $5 \mathrm{~km}$ horizontal resolution, a dry-line is found in the adjoining area of Chuadanga at 1230 UTC. During this time, the relative humidity over these three thunderstorms event area is $45 \%$ over Chuadanga and 65\% over Mymensingh and Sylhet. When a thunderstorm occurs, rainfall associated with it, increase the surface level relative humidity. From the model output, relative humidity is suddenly increased to more than $100 \%$ over Chuadanga at 1530 UTC, Mymensingh at 1730 UTC and Sylhet at 1830 UTC respectively.

For $10 \mathrm{~km}$ horizontal resolution, dryline is also found but it is not as precise as $5 \mathrm{~km}$ resolution. Relative humidity more than $100 \%$ is found over Mymensingh at 1530 UTC but it is not found over Chuadanga and Sylhet at 1530 UTC and 1830 UTC respectively. During that time, relative humidity to the most of the part of Bangladesh is $100 \%$. The model simulated relative humidity at the 2-meter height of 06 May 2017 based on the initial conditions of 0000 UTC of 05 May for $5 \mathrm{~km}$ and $10 \mathrm{~km}$ horizontal resolution is shown in Figure 5. 


\section{Vertical Cross Section of Relative Humidity}

From the model output of vertical cross section using $5 \mathrm{~km}$ horizontal grid resolution, moist air of $\mathrm{RH}$ more than $80 \%$ is found up to $950 \mathrm{hPa}$ level at 1000 UTC and during that time the RH is less than $30 \%$ above $850 \mathrm{hPa}$ level over Mymensingh. The $\mathrm{RH}$ of the surface area is started to increase in the vertical direction in $90.40 \mathrm{E}$ at 1530 UTC and an area of the moist air of $\mathrm{RH}$ more than $80 \%$ is found between $200-300 \mathrm{hPa}$ levels during that time which is an indication of Cumulonimbus cloud at this level. The vertically increasing moist air creates a vertical line of RH of more than $80 \%$ up to $200 \mathrm{hPa}$ from the surface. This line indicates the updraft and downdraft of the thunderstorm event which is gradually moved toward eastern direction due to the westerly wind with time. But in case of $10 \mathrm{~km}$ grid resolution, the moist air of $\mathrm{RH}$ of just $40-50 \%$ is found between 400 to $500 \mathrm{hPa}$ levels at $1530 \mathrm{UTC}$. Also the vertical line of $\mathrm{RH}$ more than $80 \%$ is just found up to 550 $\mathrm{hPa}$ level at $1700 \mathrm{UTC}$ as shown in Figure 6. From the above analysis, it is found that the model captures the presence of cumulonimbus cloud, updraft and downdraft over the thunderstorm events area precisely well in $5 \mathrm{~km}$ horizontal grid resolution than that of $10 \mathrm{~km}$ over Mymensingh. A similar phenomenon is also found over Chuadanga and Sylhet. That is WRF model preform precisely well in case of $5 \mathrm{~km}$ horizontal grid than that of $10 \mathrm{~km}$ horizontal grid to capture cumulonimbus cloud, updraft and downdraft over these three TS event area.

\section{Analysis of Radar Reflectivity}

Doppler Weather Radar (DWR) is now successfully used in a wide range for the study of severe weather phenomena such as thunderstorms, tornadoes, cyclones, etc. It can detect the position and strength of weather echoes as well as can measure the speed of rain or hail towards or away from the $\operatorname{radar}^{28}$. From the numerical model simulated radar reflectivity, one can easily see the details about the mesoscale and near storm scale structures such as the structure of deep convection, movement of a squall line, etc ${ }^{4}$. The radar reflectivity more than $50 \mathrm{dBZ}$ is an indication of heavy rain and sometimes associated with hail according to National Oceanic and Atmospheric Administration (NOAA) dBZ scale for weather radar. From the model simulated result for $5 \mathrm{~km}$ horizontal resolution, reflectivity value more than $50 \mathrm{dBZ}$, is found on the northern side of the Chuadanga at 1530 UTC and over Mymensingh at 1730 UTC which gradually moves toward Sylhet and passes at 1830 UTC. This is an indication of a convective cloud over this area as mention in Figure 1(b). This convective cloud produces heavy rainfall over these three thunderstorm events area. For $10 \mathrm{~km}$ horizontal resolution, supportive value of reflectivity is not found over the adjoining area of Chuadanga. It is found over the northern part of Mymensingh (over India) at 1830 UTC which passes Mymensingh at 1930 UTC and Sylhet at 2100UTC (not shown in Figure) that is almost 4 hours later than that of the time of occurrence. It is not possible to validate the value of reflectivity due to the lack of radar reflectivity of the nearest station. Model simulated reflectivity of 06 May 2017 based on the initial conditions of 0000 UTC of 05 May for $5 \mathrm{~km}$ and $10 \mathrm{~km}$ horizontal resolution is shown in Figure 7.

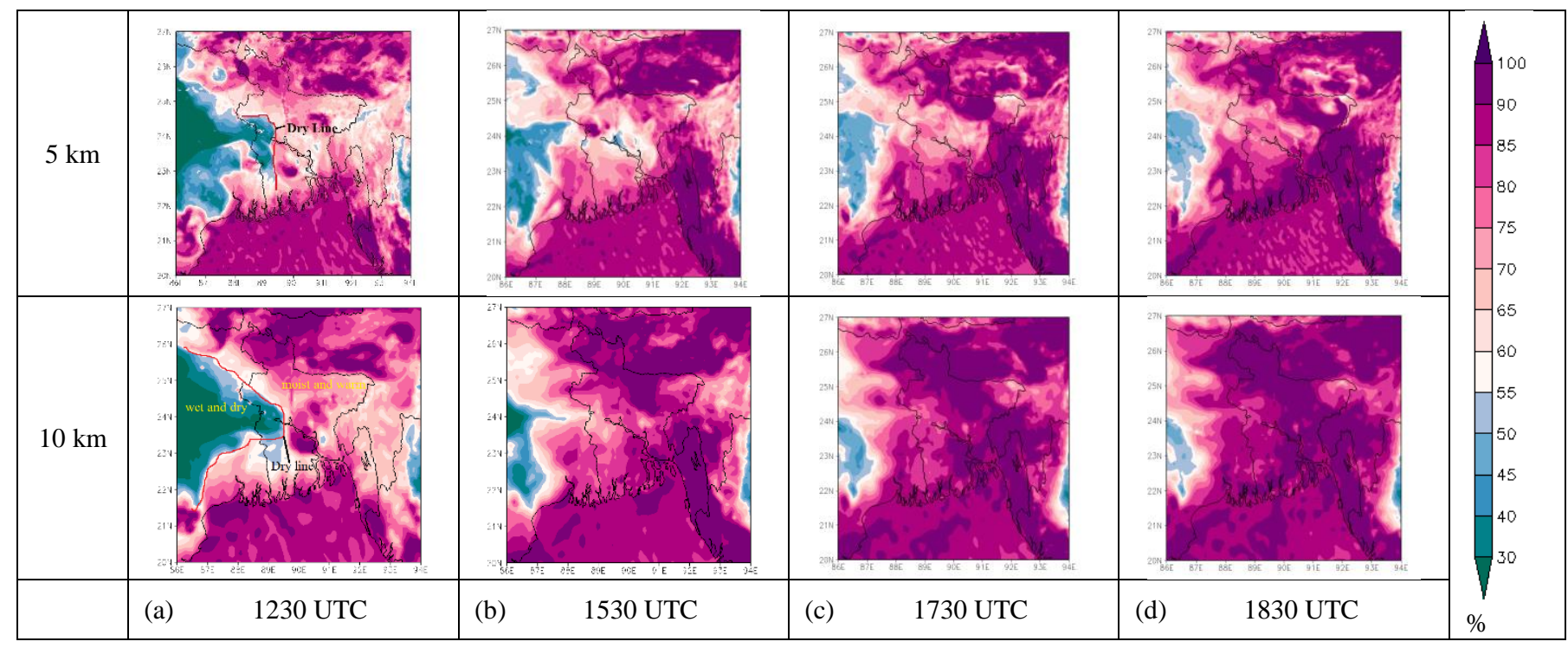

Fig. 5. Model simulated relative humidity at 2 meter height of 06 May at different times 


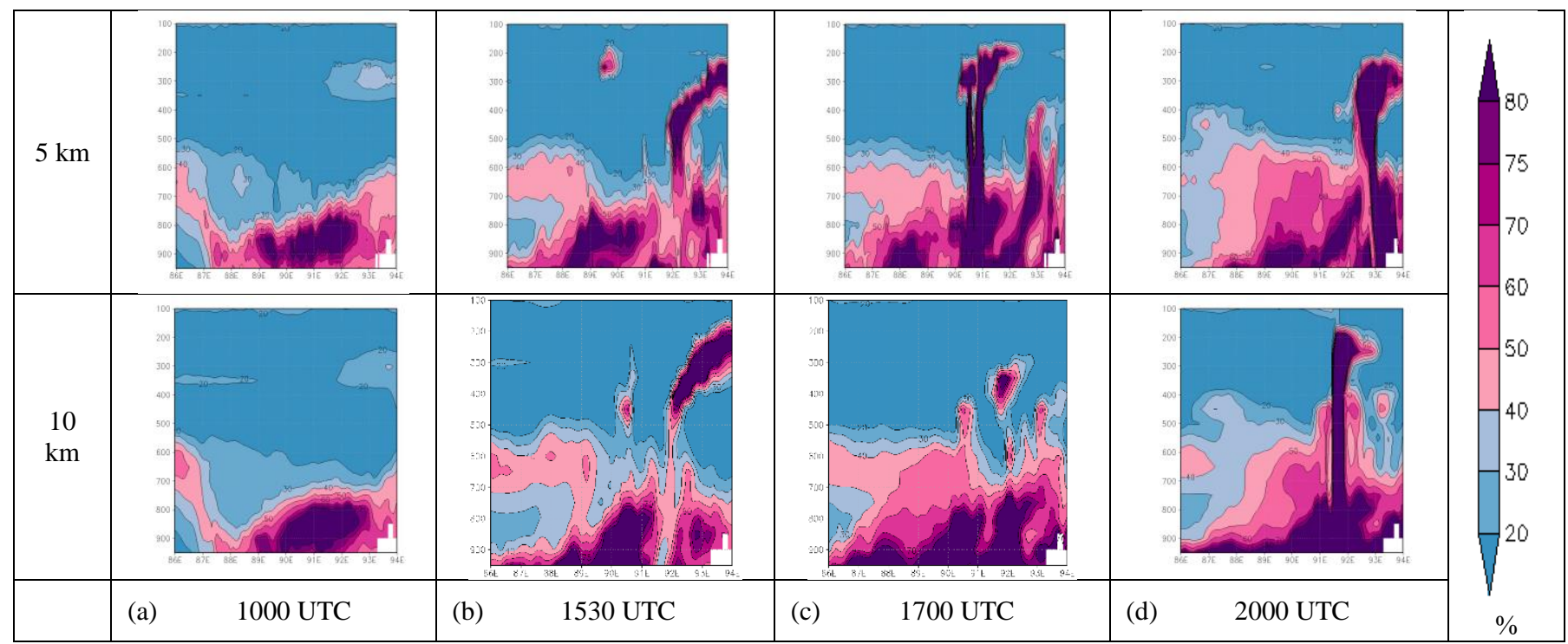

Fig. 6. Model simulated vertical cross section of relative humidity in $24.75 \mathrm{~N}$ of 06 May 2017 performed by WRF-ARW model

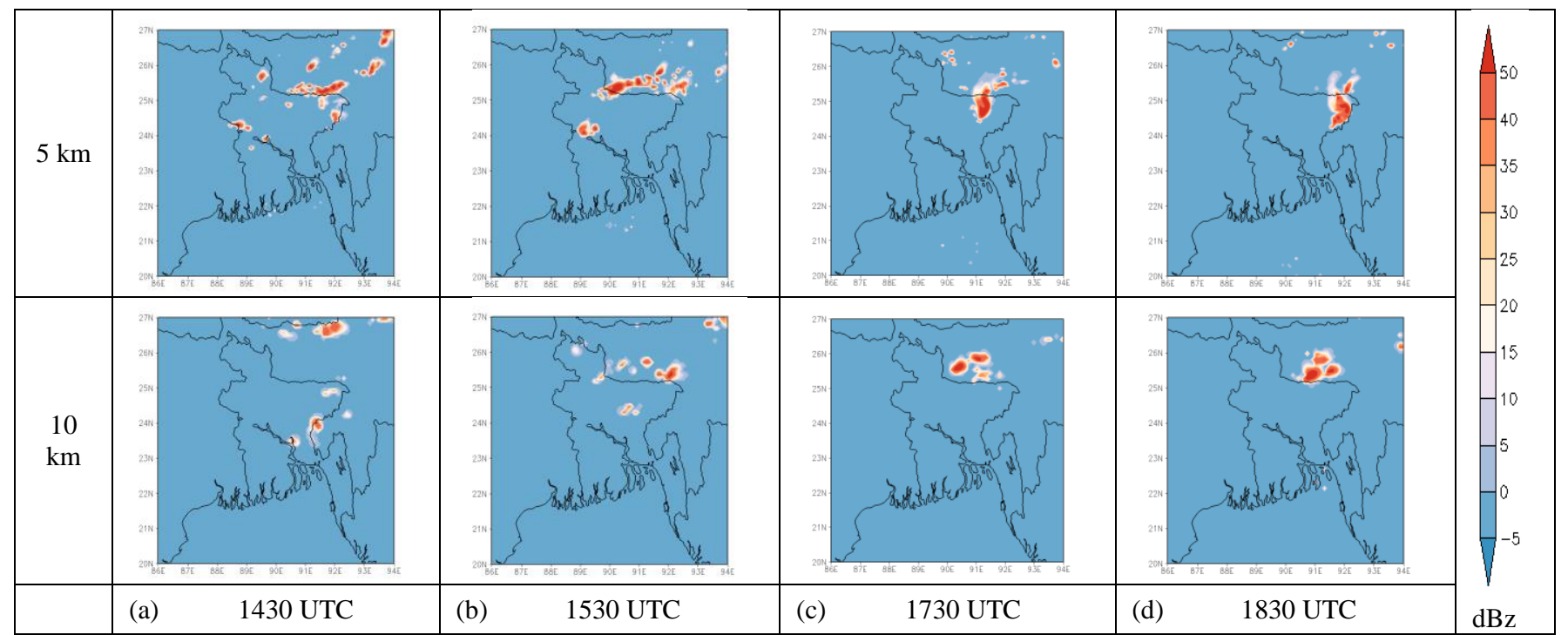

Fig. 7. Model simulated reflectivity of 06 May 2017 at different times

Analysis of CAPE at $850 \mathrm{hPa}$ Pressure Level

The amount of buoyant energy available for the vertical acceleration of a particle is known as the Convective available potential energy (CAPE). It is the maximum possible kinetic energy available for convection and gives an indication of tropospheric instability at a given time ${ }^{29}$. CAPE is calculated as the positive temperature difference between the theoretical parcel and environmental lapse rates, vertically integrated with respect to the natural logarithm of pressure, $\mathrm{p}$, between the level of free convection (LFC) and equilibrium level (EL):

$$
C A P E=\int_{L F C}^{E L} R_{g}\left(T_{v e}-T_{v p}\right) d \ln P
$$

Where, $T_{v e}$ and $T_{v p}$ are the environmental and parcel virtual temperature, $R_{g}$ is the gas constant of dry air. CAPE is measured in Joule per $\mathrm{kg}\left(\mathrm{jkg}^{-1}\right)$. CAPE values greater than
$1500 \mathrm{jkg}-1$ is required for the formation of suppercell thunderstorms ${ }^{18}$.

Model output for $5 \mathrm{~km}$ horizontal resolution shows that the supportive CAPE value for the formation of a thunderstorm is not present over the events area at 0500 UTC. The CAPE value over this area is then started to increase and become more than $1500 \mathrm{Jkg}^{-1}$ over Chuadanga and Mymensingh at 0700 UTC and over Sylhet at 0900 UTC. This strong convective potential energy helps to form a cumulonimbus cloud over this region. The CAPE value over this region is started to decrease after a few hours and become less than $1500 \mathrm{Jkg}^{-1}$ at 1900 UTC shown in Figure 8. In the case of $10 \mathrm{~km}$ horizontal resolution, supportive CAPE value also is not found at 0500 UTC over the selected event area. Then the CAPE value is started to increase over Chuadanga and become more than $1500 \mathrm{Jkg}^{-1}$ at $0700 \mathrm{UTC}$. This CAPE value is increased with time and moves toward 
Mymensingh and Sylhet and then gradually decreased with time. According to the University of Wyoming data, the available observed value of CAPE at 0000 and 1200 UTC on 06 May 2017 is 00 and $2094 \mathrm{Jkg}^{-1}$ respectively which is at Dhaka. This strong CAPE value precisely support the model simulated result for both grid resolutions.

\section{Vorticity Analysis at Surface Level (850 hPa level)}

For $5 \mathrm{~km}$ horizontal grid resolution, average vorticity over the TS event area remains positive during the early hours of the day (0400 UTC). A presence of strong positive and negative vorticity is found over the adjoining area of Chuadanga (north side) at 1530 UTC, over Mymensingh at 1700 UTC and over Sylhet at 1830 UTC respectively which describe the presence of updraft and downdraft of the TS event. This strong vorticity is gradually decayed with time which means that the TS dies out with time. But in the case of $10 \mathrm{~km}$ horizontal grid resolution, the presence of strong positive and negative vorticity is not found over Chuadanga. Although it is found over Mymensingh and Sylhet it is two hours later than that of $5 \mathrm{~km}$ grid resolution (not shown in the Figure). Model simulated vorticity at $850 \mathrm{hPa}$ level of 06 May 2017 based on the initial conditions of 0000 UTC of 05 May for $5 \mathrm{~km}$ and 10 $\mathrm{km}$ horizontal resolution is shown in Figure 9.

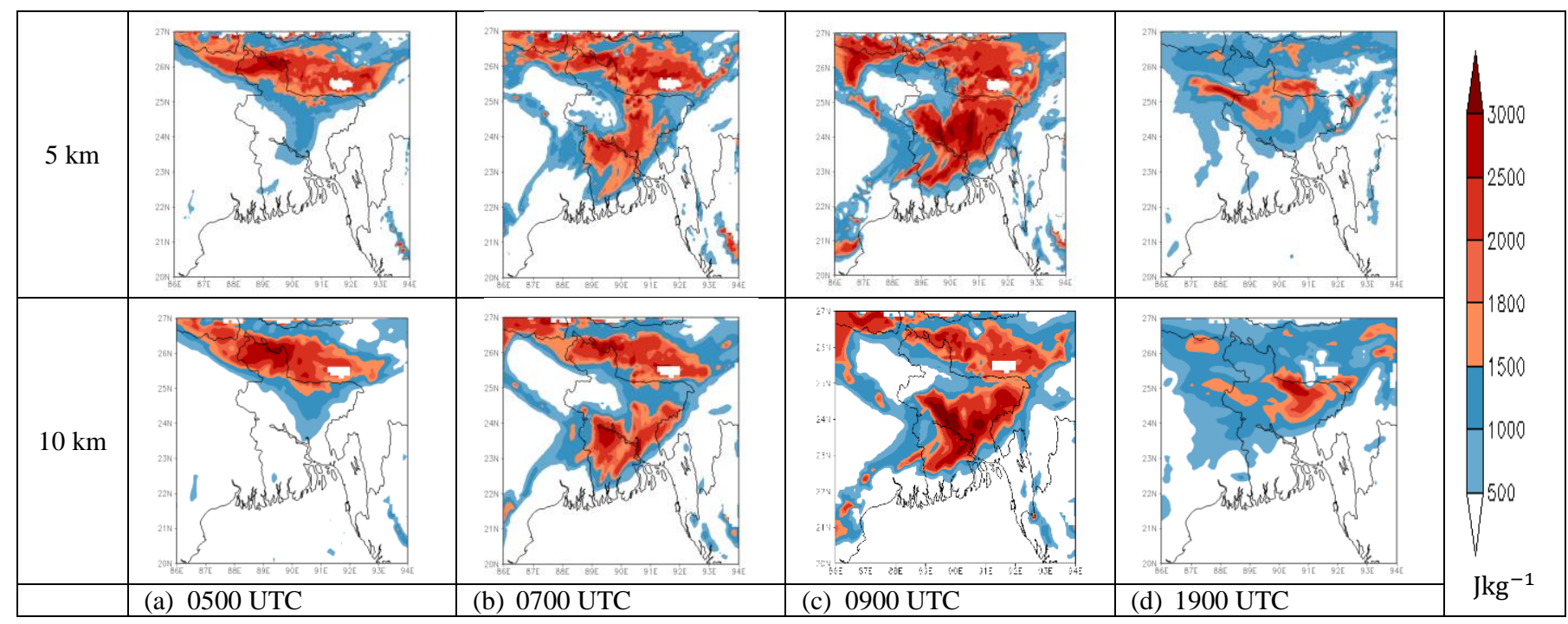

Fig. 8. Model simulated CAPE value of 06 May 2017 performed by WRF-ARW model

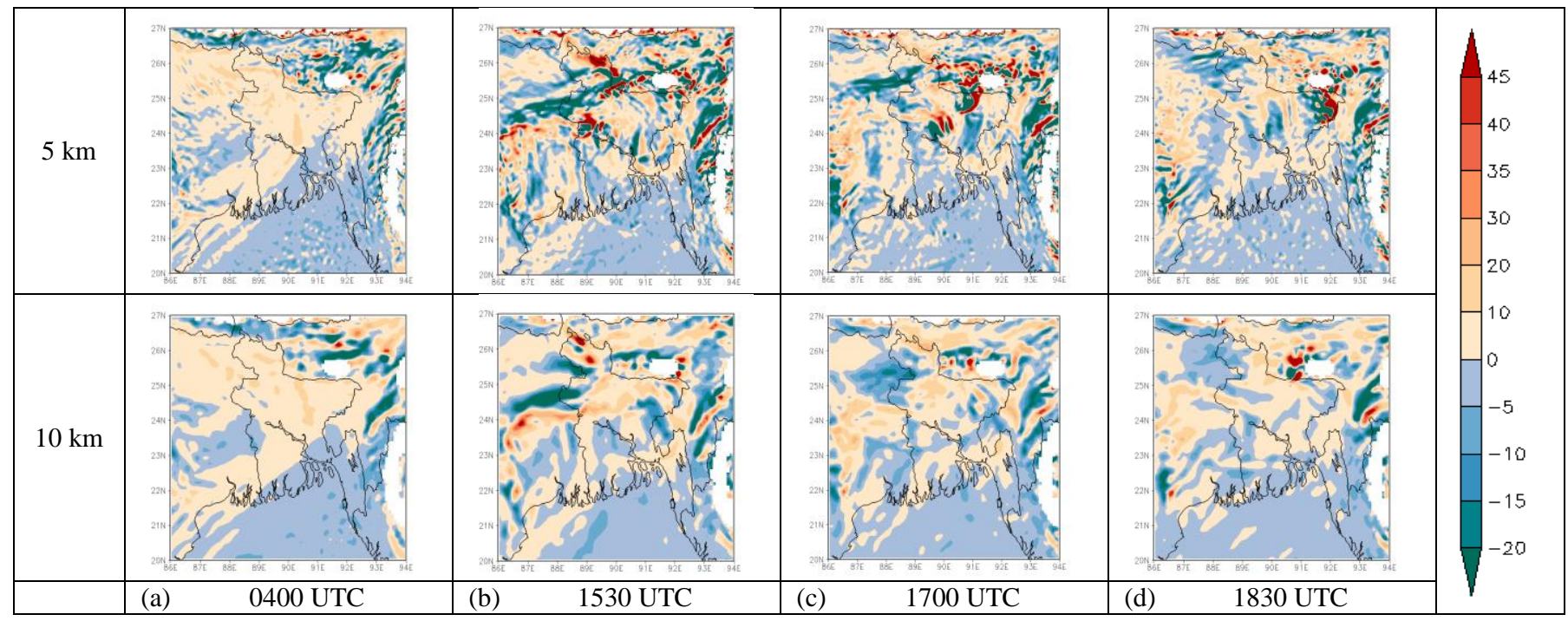

Fig. 9. Model simulated surface level vorticity of 06 May 2017 at different times 
Table 2. Statistical analysis of various meteorological parameters of 06 May 2017 using the three hourly observed data and model output.

\begin{tabular}{|c|c|c|c|c|c|c|c|}
\hline \multirow[t]{2}{*}{ Statistical analysis } & \multirow[t]{2}{*}{ Meteorological parameters } & \multicolumn{2}{|c|}{ Chuadanga } & \multicolumn{2}{|c|}{ Mymensingh } & \multicolumn{2}{|c|}{ Sylhet } \\
\hline & & $5 \mathrm{~km}$ & $10 \mathrm{~km}$ & $5 \mathrm{~km}$ & $10 \mathrm{~km}$ & $5 \mathrm{~km}$ & $10 \mathrm{~km}$ \\
\hline \multirow{3}{*}{$\begin{array}{l}\text { Root mean square } \\
\text { error (RMSE) }\end{array}$} & MSLP & 1.04 & 1.62 & 0.43 & 0.77 & 0.65 & 0.93 \\
\hline & Relative humidity $(\mathrm{RH})$ & 15.48 & 19.40 & 7.40 & 7.37 & 10.26 & 13.10 \\
\hline & wind speed at $850 \mathrm{hPa}$ level & 30.14 & 32.21 & 15.95 & 24.82 & 36.14 & 35.0 \\
\hline \multirow{3}{*}{$\begin{array}{l}\text { Mean absolute error } \\
\text { (MAE) }\end{array}$} & MSLP & 0.75 & 1.25 & 0.33 & 0.68 & 0.58 & 0.87 \\
\hline & RH & 12.75 & 17.38 & 6.25 & 5.86 & 7.5 & 10.0 \\
\hline & wind speed at $850 \mathrm{hPa}$ level & 27.62 & 29.0 & 14.25 & 18.13 & 26.62 & 27.88 \\
\hline \multirow{3}{*}{$\begin{array}{l}\text { Correlation } \\
\text { coefficient (CC) }\end{array}$} & MSLP & 0.90 & 0.81 & 0.98 & 0.97 & 0.95 & 0.90 \\
\hline & $\mathrm{RH}$ & 0.78 & 0.65 & 0.78 & 0.77 & 0.78 & 0.66 \\
\hline & wind speed at $850 \mathrm{hPa}$ level & 0.69 & 0.53 & 0.88 & 0.75 & 0.05 & -0.06 \\
\hline
\end{tabular}

Statistical Analysis of Meteorological Parameters

Some comparative statistical analyses of different meteorological parameters simulated by the model with the 3 hourly observed data from 00-00 UTC (24 hours) are made for both $5 \mathrm{~km}$ and $10 \mathrm{~km}$ horizontal grid resolution which is shown in Table 2. It is seen that model output for 5 $\mathrm{km}$ horizontal grid resolution is better than that of a $10 \mathrm{~km}$ grid resolution. But, in case of wind speed at $850 \mathrm{hPa}$ level the root mean square error, mean absolute error and correlation coefficient are very poor over Sylhet for both grid resolution. The correlation coefficient is 0.05 and -0.06 respectively. It is mentioned in the previous section that the strong wind blows over Sylhet at 1800 UTC and 2100 respectively, but the actual event was occurred around 1500 UTC and here three hourly data is used. So this temporal error of wind speed strongly affects the analysis over Sylhet. However, considering the other statistical analysis, it can be said that the WRF-ARW model with smaller horizontal grid resolution $(5 \mathrm{~km})$ has better simulated the meteorological parameters.

\section{Conclusion}

The present study is made to simulate a severe thunderstorm event observed over Mymensingh, Sylhet, and Chuadanga on 06 May 2017 using a high-resolution WRF Model with $5 \mathrm{~km}$ and $10 \mathrm{~km}$ grid spacing. This study was taken up to scrutinize the ability of the WRF Model to simulate the main features of the thunderstorm and to examine the impact of the horizontal grid resolution for simulating TS event. After analyzing the various features during the thunderstorm, it is found that the model can simulate many features of the thunderstorm precisely well in case of a $5 \mathrm{~km}$ horizontal grid resolution than that of 10 $\mathrm{km}$ but with some differences.

First of all, the low-pressure area which is a very important ingredient for TS formation is captured by the WRF-ARW model precisely well for $5 \mathrm{~km}$ grid than that of $10 \mathrm{~km}$ grid spacing. In case of wind pattern and direction, a conjugation of easterly and westerly wind is found in both of the cases and the model can capture the strong wind over the TS event area for both $5 \mathrm{~km}$ and $10 \mathrm{~km}$ grid size. But it is almost one hour later than that of the observation for 5 $\mathrm{km}$ grid and for $10 \mathrm{~km}$ grid it is two to three hours later.
From the model output, it is also found that strong vertical wind shear between $850 \mathrm{hPa}$ level and $200 \mathrm{hPa}$ level is captured well in the case of $5 \mathrm{~km}$ grid spacing. Also from the analysis of model output, it is found that the model captures the presence of cumulonimbus cloud, updraft and downdraft over Mymansingh precisely well in $5 \mathrm{~km}$ horizontal grid resolution than that of $10 \mathrm{~km}$. A similar phenomenon is also found over Chuadanga and Sylhet. Radar reflectivity $(\mathrm{dBz})$ of the Model output shows that the presence of the convective cloud is found over the event areas in case of $5 \mathrm{~km}$ grid spacing which is almost one hour later but for $10 \mathrm{~km}$ grid spacing it is almost 4 hours later and not exactly over the event areas. Model simulated result for CAPE value shows that CAPE value supportive for TS formation is found almost similar over the event areas for both the cases. So the horizontal grid resolution has less impact over CAPE value. The presence of strong positive and negative vorticity in parallel, that is the presence of updraft and downdraft, is found very well for $5 \mathrm{~km}$ grid spacing which is not good enough for $10 \mathrm{~km}$ grid spacing.

From the above discussion, it is suggested that the WRF ARW model with lower horizontal grid resolution $(5 \mathrm{~km})$ perform well to capture the main features of the TS event than that of higher grid resolution $(10 \mathrm{~km})$ except the CAPE value with some temporal and position error. So we can conclude that WRF-ARW model output for $5 \mathrm{~km}$ grid resolution can be used to forecast future TS events over Bangladesh but we need more study to minimize the error.

\section{References}

1. Rahman, S.M.M., S.M. Hossain and M. Jahan, 2019. Thunderstorms and Lightning in Bangladesh. Bangladesh Medical Research Council Bulletin, 45(1), 1-2 .DOI: 10.3329/bmrcb.v45i1. 41801

2. Kessler, E, 1982. Thunderstorm morphology and dynamics. US Department of Commerce, National Oceanic and Atmospheric Administration.

3. Karmakar, S, 2001. Climatology of thunderstorm days over Bangladesh during the pre-monsoon season. Journal of Bangladesh Academy of Sciences, 03,103-112.

4. Namias J, 1938. Thunderstorm forecasting with the aid of isentropic charts. Bulletin of the American Meteorological Society, 19, 1-14. 
5. Reynolds, G. S., M. Brook and M. F. Gourley, 1957. Thunderstorm charge separation. Journal of Meteorology, 14, 426-436.

6. Lemon, L. R., III C. A. 1979. Severe thunderstorm evolution and mesocyclone structure as related to tornadogenesis. Monthly Weather Review, 107, 1184-1197.

7. Lilly, D. K. 1990. Numerical prediction of thunderstormshas its time come? Quarterly Journal of the Royal Meteorological Society, 116, 779-798.

8. Tyagi, B., V. N. Krishna and A. Satyanarayana. 2011. Study of thermodynamic indices in forecasting pre-monsoon thunderstorms over Kolkata during STORM pilot phase 2006--2008. Natural hazards, 3, 681-698. doi: https://doi.org/10.1007/s11069-010-9582-x

9. Das, M. K., M. A. Chowdhury, S. Das, S. K. Debsarma and S. Karmakar. 2015a. Assimilation of Doppler weather radar data and their impacts on the simulation of squall events during pre-monsoon season. Natural Hazards 77(2), 901931. doi.org/10.1007/s11069-015-1634-9

10. Ahasan, M., D. Quadir, K. A. Khan and M. Haque. 2015. Simulation of a thunderstorm event over Bangladesh using WRF-ARW model. Journal of Mechanical Engineering, 44, 124-131.

11. Karmakar, S., D. A. Quadir and M. K. Das. 2017. Numerical simulation of physical and dynamical characteristics associated with the severe thunderstorm on April 5, 2015 at Kushtia and Jhenaidah. Natural Hazards, 86(3), 1127-1146. doi:10.1007/s11069-016-2733-y

12. Litta, A., Mary Ididcula S., U. Mohanty and S. Kiran Prasad. 2012. Comparison of thunderstorm simulations from WRF-NMM and WRF-ARW models over east indian region. The Scientific World Journal, 2012, 20.

13. Singh J., A. Gairola, S. Das 2015. Numerical Simulation of a Severe Thunderstorm over Delhi Using WRF Model. International Journal of Scientific and Research Publications, 5(6), 327-332.

14. Das, S., A. Sarkar, M. K. Das, M. M. Rahman and N. Islam. 2015c. Composite characteristic of Nor'westers based on observation and simulation. Atmospheric research, 158, 158-178.

15. Das, M., M. Chowdhury, S. Das. 2015b. Sensitivity study with physical parameterization schemes for simulation of mesoscale convective systems associated with squall events. Int J Earth Atmos Sci, 2(2), 20-36.

16. Rajeevan, M., A. Kesarkar, S. Thampi, T. Rao, B. Radhakrishna and M. Rajasekhar. 2010. Sensitivity of WRF cloud microphysics to simulations of a severe thunderstorm event over Southeast India. Annales Geophysicae, 28, 603619.

17. Zeyaeyan, S., E. Fattahi, A. Ranjbar, M. Azadi and M. Vazifedoust, 2017. Evaluating the effect of physics schemes in WRF simulations of summer rainfall in north west Iran. Climate, 5(3), 48. Available at https://doi.org/10.3390/cli50 30048
18. Prediction N. C., Service N. W., NOAA, Commerce U. D. 2018. NCEP FNL Operational Model Global Tropospheric Analyses, continuing from July 1999. Research Data Archive at the National Center for Atmospheric Research, Computational and Information Systems Laboratory. Available at https:// rda .ucar .edu/datasets/ds083.2/

19. Guide, W. U. (n.d.). User's Guide for the Advanced Research WRF (ARW) ModelingSystem Version 3.8. Available at http://www2.mmm.ucar.edu/wrf/users /docs/user_guide_V3/contents.html

20. Kessler, E. 1969. On the distribution and continuity of water substance in atmospheric circulations. Meteor. Monogr 32,1-48. doi:10.1007/978-1-935704-36-2_1

21. Hong, Song-You, Yign, Noh, Jimy and Dudhia. 2006. A new vertical diffusion package with an explicit treatment of entrainment processes. Mon. Wea.Rev. 134, 2318-2341.

22. Jimenez, Pedro A., Jimy Dudhia, J. Fidel Gonzalez-Rouco, Jorge Navarro, Juan P. Montavez, and Elena GarciaBustamante, 2012. A revised scheme for the WRF surface layer formulation. Mon. Wea. Rev. 140, 898-918. doi: 10.1175/MWR-D-11-00056.1

23. Tewari, M., F., Chen W. Wang, J. Dudhia, M. A. LeMone, K. Mitchell, M. Ek, G. Gayno, J. Wegiel, and R. H. Cuenca. 2004. Implementation and verification of the unified NOAH land surface model in the WRF model. 20th conference on weather analysis and forecasting/16th conference on numerical weather prediction, pp. 11-15.

24. Dudhia, J., 1989. Numerical study of convection observed during the Winter Monsoon Experiment using a mesoscale two-dimensional model. J. Atmos. Sci. 46,30773107.doi:10.1175/1520-0469

(1989)046<3077:NSOCOD>2.0.CO;2

25. Mlawer, Eli. J., Steven. J. Taubman, Patrick. D. Brown, M. J. Iacono, and S. A. Clough,1997. Radiative transfer for inhomogeneous atmospheres: RRTM, a validated correlated-k model for the longwave. J. Geophys. Res. 102,16663-16682. doi:10.1029/97JD00237

26. Grell, G. A. 2002. A generalized approach to parameterizing convection combining ensemble and data assimilation techniques. Geophysical Research Letters, 29,38-1. doi:10.1029/2002 GL 015311

27. Saha, T. R., and D. A. Quadir, 2016. Variability and trends of annual and seasonal thunderstorm frequency over Bangladesh. International Journal of Climatology, 36(14), 4651-4666.

28. Bhatnagar, A., P. R. Rao, S. Kalyanasundaram, S. Thampi, R. Suresh and J. Gupta, 2003. Doppler radar--A detecting tool and measuring instrument in meteorology. Current Science, 85, 256-264.

29. Holley, D., S. Dorling, C. Steele and N. Earl. 2014. A climatology of convective available potential energy in Great Britain. International Journal of Climatology, 34, 3811-3824. 
